\title{
Committee Chair's Majority Partisan Status and Its Effect on Information Transmission via Hearings
}

Ju Yeon Park, School of Computing and Information, University of Pittsburgh

\begin{abstract}
While US Congress assigns only the members of a majority party to committee chairs, some state legislatures and other legislative bodies using a proportional representation system also consider members of a minority party for the position to promote a bipartisan policy making practice. Although previous literature investigates the effects of bipartisan rules and practices exploiting such institutional variations, the informational benefit of having a minority partisan committee chair has not been explored. By extending a recent study by Park (2017), this research note theoretically examines the effect of the committee chair's majority partisan status on information acquisition and transmission via committee hearings. Findings suggest that under some conditions, the floor can informationally benefit more from having a chair representing a minority party in the chamber with opposite bias call a hearing than with a chair representing a majority party.
\end{abstract}

Keywords: Informational theory, committees, agenda-setting, hearing, information transmission, grandstanding

\section{Introduction}

Some US state legislatures introduced rules and norms of procedures that promote bipartisan policy-making to help the minority party better represented (e.g. neutralizing committee chairs' agenda setting power by requiring all bills to be heard or reported to the floor, or diffusing such power to members of the minority party). ${ }^{1}$ Scholars have shown that the measures neutralizing

\footnotetext{
1 “Best Practices for Collaborative Policymaking” by Bipartisan Policy Center. https://d3n8a8pro7vhmx.cloudfront.net/fairvote/pages/611/attachments/original/1450119526/Bes $\underline{\text { t-Practices-for-Collaborative-Policymaking.pdf?1450119526 }}$
} 
agenda-setting power at committee-level tend to enhance legislatures' bipartisan collaboration (Anzia \& Jackman, 2013; Cox et al., 2010), efficiency (Martorano, 2004) and productivity (Jackman, 2014). However, the effect of appointing a minority partisan committee chair has received relatively less attention. Furthermore, the informational benefit of such measures has not been studied yet. Thus, this research note investigates whether having members of the minority party chair a committee helps the committee better function as an information mediator for the floor under certain conditions.

While minority party members do not chair committees in the US Congress, there are some instances that US state legislatures assign members of a minority party as committee chairs (Hedlund \& Hamm, 1996), ${ }^{2}$ and it is more common in proportional representation systems (e.g. Austria, Belgium, Denmark, Germany, Netherlands, Norway, Sweden and Switzerland) where the rules of procedures explicitly require committee chairs' positions to be proportionately shared by parties sitting in the parliament (Powell \& Whitten, 1993).

A committee chair who is a member of the majority party, which I call a "majority chair," often possesses extensive authority over a legislative decision-making process within a

${ }^{2}$ In their study of political parties in US state legislative committees, the authors report that in 98 chambers during the $1977-8$ session, 28 out of the 1,643 committee chairs ( 1.7 per cent) were members of a minority party. These cases are mostly from the following six chambers - the Senates in Alaska, California, Tennessee and Vermont, and the lower houses in California and Vermont, and their mean percentage of committees with a minority chair was 25.6 per cent. During the 1989-90 session, they find that the percentage of minority chairs increased three-fold to 5.1 per cent. 
committee (Cox \& McCubbins, 2005; De Gregorio, 1992). For example, he can set committee agenda by deciding whether to hear a bill or not and has a great deal of discretion over the selection of witnesses to testify in hearings.

On the other hand, despite being a chair of a committee, the ability of a chair who is a member of the minority party, which I call a "minority chair," to move his bills forward can be limited in two dimensions. First, a minority chair is less likely to secure a majority vote support in his favor on divisive policy issues within a committee as well as on the floor than a majority chair. In such cases, the chair's agenda-setting power significantly weakens (Evans, 1991, p. 53). Second, although legislative chambers often specify a minority party's right to call witnesses in their rules of procedures to ensure the minority's representation, the extent of such right of a minority chair is unlikely to be as great as that of a majority chair. For example, the German Bundestag allows minority members to call witnesses when they request a hearing; however, if a committee limits the number of witnesses, they can call a proportion of persons to be heard corresponding to their relative strength in the committee (Rule 70-(2)). ${ }^{3}$

Given the differences between a majority chair and a minority chair in their amount of discretion over agenda-control and hearing procedures, the chair's majority partisan status can be an important factor affecting his decision to hold a hearing, the nature of the hearing, and its outcomes. Therefore, this research note investigates when each of a majority chair and a minority

\footnotetext{
${ }^{3}$ The US Congress has a similar rule such that minority members of a committee can invite witnesses for at least one day of hearings when majority of them sends a written request to the chairman (RULE XI, 2(j)(1) in the House, and Rule XXVI, paragraph 4(d) in the Senate).
} 
chair holds a hearing and how informative the hearings that each one holds are. To do so, I utilize and extend the theoretical model on committee decision-making by Park (2017).

Park (2017)'s model is especially suitable for this study for the following reasons. First, while other existent informational models (e.g. Diermeier \& Feddersen, 2000; Gilligan \& Krehbiel, 1987) assume a committee as a unitary actor, her model assumes a committee composed of two members with heterogeneous preferences with one representing a majority party and the other representing a minority party. Although Gilligan and Krehbiel (1989) also assume heterogenous committee members, the resource disparity between the members, which is unique in her model, makes it readily available to compare the case where the majority member chairs the committee to the case where his minority counterpart does so.

Second, her model incorporates electoral incentives of committee members to use hearings for political grandstanding which was absent in the existent informational models but considered one of the major goals that members pursue during hearings in empirical congressional studies (De Gregorio, 1992; Huitt, 1954; Park, 2019). Thus, each member can choose to commit their resources to either information-seeking or grandstanding or even to a mixture of them if one has enough resources to allocate to both, and these decisions are symbolized to choosing witnesses of different types: an informative one and a political one. In this way, her model allows the level of information transmitted in hearings to be endogenously determined by committee members, rather than exogenously given as in other models, making it possible to test the informational benefit of varying institutions at a more precise scale.

This research note not only extends the informational models of committees and the scholarship examining the effect of introducing bipartisan rules to the legislative procedures as discussed above, but it also contributes to the following strands of literature. First, it contributes 
to the previous works studying various factors affecting the extent of information transmission in committee hearings - such as committee types (DeGregorio, 1992; Evans, 1991; Park, 2019), policy preferences of committee members and the floor pivot, the political salience of the issue (Park, 2017) and chair's seniority and ideological extremism (Kasniunas, 2011) - by introducing a new explanatory factor: the chair's majority partisan status.

Second, it extends the literature on the role of chairs and interactions between majority and minority members within a committee (DeGregorio, 1992; Evans, 1991) by systematically theorizing the incentive structure and institutional constraints using a formal model which has often been illustrated in anecdotal case studies and by additionally considering a case with a minority chair which has rarely been discussed.

The next section briefly summarizes Park's model setup and theoretical predictions and then further solve for a minority chair's hearing decisions, which was absent in the original model, to compare the decisions of a majority chair and a minority chair and the informativeness of hearings that each one holds.

\section{Model}

The model assumes two possible states of nature $s=\{0,1\}$ with the true state unknown. However, there is a prior belief that $P(s=0)=.5$, which is common knowledge. Also, suppose there exist two policy alternatives $x \in\{0,1\}$. 
The game is played by three strategic actors: the principal $(F)$ and two members of a standing committee, $\mathrm{R}$ and $\mathrm{B}$. Either of the members serves as a chair of the committee. ${ }^{4}$ It is assumed that all players try to maximize von Neumann Morgenstern expected utility.

Each committee member's utility is shaped by a combination of two components: policy-based utility and political utility. First, the policy-based utility, $u_{i}(x, s)$ for $i \in\{R, B\}$, is determined by the true state, the policy implemented, and their identity:

$$
u_{R, F}(x, s)\left\{\begin{array} { l l } 
{ 1 , } & { \text { if } x = s = 0 } \\
{ 1 - d , } & { \text { if } x = s = 1 } \\
{ 0 , } & { \text { otherwise } }
\end{array} \quad u _ { B } ( x , s ) \left\{\begin{array}{ll}
1, & \text { if } x=s=1 \\
1-d, & \text { if } x=s=0 \\
0, & \text { otherwise }
\end{array}\right.\right.
$$

Here, $d$ captures the level of policy disagreement between the two members such that when $d>0$, R prefers policy 0 ex ante, and B prefers policy 1 . Below presents the expected policy-based utility for a member:

$$
E\left(u_{i}(x, s)\right)=\sum_{s \in X}\left\{u_{i}(x, s) * P(x \mid s)\right\}, \text { for } i \in\{R, B\}
$$

Second, the political utility, $u_{i}\left(a_{i}\right)$, is the number of advocates $\left(a_{i}\right)$ that each individual member invites multiplied by $q \geq 0$ which represents the marginal benefit of inviting an advocate and is assumed to be exogenously determined.

$$
\begin{gathered}
u_{i}\left(a_{i}\right)=a_{i} * q, \text { for } i \in\{R, B\} \\
(0 \leq q)
\end{gathered}
$$

\footnotetext{
${ }^{4}$ Note that although the model assumes a two-party competition, it can be applied to a multiparty context given that coalition politics often results in a competition between two largest coalitions.
} 
There is a cost (c) that each committee member has to pay when a hearing is held since the committee members have to invest their limited time and resources to participate in a hearing. Thus, if a hearing is held, the expected utility for a committee member is as below:

$$
E U_{i}=\sum_{s \in S}^{x \in X}\left\{u_{i}(x, s) * P(x \mid s)\right\}+u_{i}\left(a_{i}\right)-c, \text { for } i \in\{R, B\} .
$$

If a hearing is not held, it reduces just to the expected policy-based utility.

The intuition behind this setup of the committee member's expected utility is as follows. First, policy-based utility provides the committee members with an incentive to seek for policyrelevant information. This incentive reduces as their policy preferences diverge from each other.

Second, political utility motivates a member to grandstand in a hearing. In practice, a member can grandstand by making statements promoting his own view, by inviting witnesses whose testimony will advocate his view, or by inviting his political opponent as a witness in order to publicly criticize her. However, this set of behaviors are simplified as inviting an advocate in the model. By grandstanding, a member may send political messages to affect the public perception in his favor and eventually garner electoral gains. The political value of grandstanding can be determined by myriads of factors, including the issue salience for example. Thus, the model assumes that the marginal benefit of inviting an advocate $(q)$ to be exogenously given.

Often the floor pivot, the principal that legislative committees report to, is not completely indifferent between policy alternatives but rather has preference for one policy over the other ex ante. This is more so on a policy issue on which floor members are highly polarized. To address this situation, the principal is assumed to share the policy preference of the majority member R. 
The game proceeds in the following order:

1. Nature chooses the state of the world with known probability .5 .

2. The chair of the committee decides whether to hold a hearing or not at a cost.

3. If a hearing is held, both members of the committee simultaneously select witnesses from three information groups.

4. Each of the selected witnesses sends a public message to the committee members and the principal.

5. With or without a hearing, the principal selects a policy based on the information she has, and payoffs are realized.

If a hearing is held, I assume that $\mathrm{R}$ has to invite two witnesses and B invites one. Thus, $\mathrm{R}$ is considered a majority member, and $\mathrm{B}$ a minority member. The reason for restricting the total number of witnesses to be invited to three is because it is the smallest possible number that makes one person invites more witnesses than the other so that the equilibrium solution is derived in the simplest fashion without loss of generality. ${ }^{5}$

The committee members can invite witnesses from three interest groups: Red, Blue, and Green. When a witness is called, she sends a message, $m_{x}$ with $x \in\{0,1\}$, supporting either of the two policy alternatives. I assume that Red witnesses always send a message in favor of policy 0 , and Blues in favor of policy 1 . However, Greens send a message that matches the true state with probability $\theta$, given $.5<\theta \leq 1$. Thus, $\theta$ is the level of accuracy of the Green witnesses. Therefore, prior to learning the true state of the world at the end of the game, Greens are

\footnotetext{
${ }^{5}$ I tried other larger numbers of witnesses with one person inviting more witnesses than the other, but the major implications of the model remain almost the same.
} 
considered a neutral information source whereas Reds and Blues are biased. All players are assumed to be aware of different information quality of the three groups of witnesses. The witnesses in this model are non-strategic actors.

The witness selection stage in this model symbolizes committee members' strategic commitment of their resources to either or a combination of two different types of behavior they can choose from when participating in a hearing: information-seeking and grandstanding. Such a commitment choice is modeled as selecting either an informative witness or an advocacy type, and the number of witnesses each member can call represents the asymmetric amount of discretion that each of a majority member and a minority member possesses over hearing procedures. ${ }^{6}$

Because the member R prefers policy 0 and B prefers policy 1 whenever $d>0$, we can consider Red witnesses as advocates for R and Blues as advocates for B. Indeed, the equilibrium will solve that R does not invite any Blues and B does not invite any Reds since these strategies are strongly dominated. Let $a_{R}$ be the number of Reds invited; $a_{B}$ the number of Blues invited; $g_{i}$, for $i \in\{R, B\}$, the number of Greens invited by the member $i$ such that $g=g_{R}+g_{B}$. Then, $\mathrm{R}$ invites $g_{R}+a_{R}$ number of witnesses which is two, and B invites $g_{B}+a_{B}$ which should be one.

At the final stage of the game, the principal chooses one policy alternative with or without information collected from a hearing. If a hearing is not held, she always chooses policy

\footnotetext{
${ }^{6}$ Therefore, the witnesses are assumed to be a non-strategic actor although treating them as strategic actors may extend the model highlighting other interesting aspects on the interactions between the members and witnesses.
} 
0. If a hearing is held, she decides based on the Greens' messages which will update her posterior belief about the state.

For the equilibrium solution, backwards induction and the Perfect Bayesian Equilibrium are used. Solutions and proofs are provided in the online appendix. Now I explain equilibrium strategies and comparative statics.

First, the principal's policy decision is made as follows. Let $g_{m}$ be the number of Greens sending a message $m \in\{0,1\}$, such that $g=g_{0}+g_{1}$. Since the principal is biased in favor of policy 0 by $d$, if a hearing is not held, the principal always selects policy 0 . When a hearing is held, she selects policy 0 , if $g_{0} \geq g_{1}$, or if $g_{0}<g_{1}$ and $d>1-\left(\frac{\theta}{1-\theta}\right)^{\left(g_{0}-g_{1}\right)}$; and policy 1 , otherwise. However, if she is indifferent about choosing either of the policies, she randomizes her choice with .5 probability.

Second, if a hearing is held, there are three types of pure-strategy equilibria for witness selection which translate to three different types of hearings. First, R invites two Reds, and B invites a Blue. This equilibrium is labeled as ' $\mathrm{NG}$ ' meaning no Greens and implies a hearing where all committee members grandstand. Second, $\mathrm{R}$ invites two Greens, and B also invites a Green. This equilibrium is labeled as 'AG' meaning all Greens and stands for a fully informative hearing. The third type is characterized as a partially informative hearing in which only one Green is invited in total of three witnesses. This includes two equilibria: One in which R invites one Green and one Red, and B invites a Blue; the other in which R invites two Reds, and B invites a Green. The former is labeled as 'SG1' and the latter as 'SG2,' and here SG means some Greens.

Let $\Delta P(n)$ be the marginal probability of implementing a correct policy by inviting the $\mathrm{n}^{\text {th }}$ number of one additional Green witness such that $\Delta P(n) \equiv P(x=s \mid g=n)-$ 
$P(x=s \mid g=n-1) ; \varphi$ the probability that the principal chooses policy 0 even if $g_{0}<g_{1}$ such that $\left.\varphi \equiv P\left(d>1-\left(\frac{\theta}{1-\theta}\right)\right)^{\left(g_{0}-g_{1}\right)} \mid g_{0}<g_{1}\right) ; \varphi_{g}$ the value of $\varphi$ when the total number of Greens invited is $g$; and $\lambda \equiv\left(1-\frac{1}{2} d\right)$ for notational brevity.

Each of the three equilibria exist under the following conditions: NG if $q \geq$ $\left(1-\varphi_{1}\right)\left(\theta \lambda-\frac{1-d}{2}\right) ; \mathrm{AG}$ if $q \leq \frac{\Delta P(3) * \lambda(1-\varphi)}{2} ; \mathrm{SG} 1$ if $q \leq\left(1-\varphi_{1}\right)\left(\theta \lambda-\frac{1-d}{2}\right) ; \mathrm{SG} 2$ if $\frac{\Delta P(3) * \lambda(1-\varphi)}{2} \leq q \leq\left(1-\varphi_{1}\right)\left(\theta \lambda-\frac{1-d}{2}\right)$. Figure 1 summarizes the three equilibria of witness selection as a function of $q$ and $d$ assuming $\theta=.8$ and also marks the expected hearing decisions by a committee chair which will now be explained.

Third, the model predicts that a majority chair holds a hearing if $p\left(1-\frac{1}{2} d\right)(1-\varphi)+$ $\frac{\varphi}{2}+a_{R} * q-.5>c$; a minority chair holds a hearing if $p\left(1-\frac{1}{2} d\right)(1-\varphi)+\frac{\varphi(1-d)}{2}+a_{B} *$ $q-\frac{1-d}{2}>c$; and both chairs hold a hearing with .5 probability when indifferent. Thus, a majority chair is more likely to hold a hearing than a minority chair if $2 q\left(a_{R}-a_{B}\right)>d(1-\varphi)$. The value of $\varphi$ is either 0 or 1 depending on the size of $g_{0}, g_{1}$ and $d$ (See online appendix for computation of $\varphi$ ). When $\varphi=1$, the majority chair is more likely to hold a hearing if $a_{R}>a_{B}$ which is satisfied when SG2 or NG is expected in the next stage. If $\varphi=0$, the chair's hearing decision also depends on $q$ and $d$. For example, if $d$ is low and $q$ is high enough and either SG2 or NG is expected $\left(a_{R}>a_{B}\right)$, then a majority chair is more likely to hold a hearing than a minority chair. However, if $q$ is low enough so that AG or SG1 is likely to occur $\left(a_{R}=a_{B}\right)$, then a minority chair is more likely to hold a hearing than a majority chair.

These comparative statics make two interesting points. One is that a minority chair has a stronger incentive to hold a hearing as the benefit of inviting an advocate $(q)$ becomes trivial and 
the level of disagreement $(d)$ increases to some extent. More intuitively, when the majority member has less motivation for a hearing because the principal shares the common view, the minority would want to hold a hearing and let a Green witness testify. That is because inviting at least one Green may dramatically increase the chances of implementing the minority's preferred policy if the Green testifies in support of that policy while not holding a hearing will completely rule out this possibility.

The other more interesting implication is that a majority chair has a stronger incentive to hold a hearing when he intends to grandstand in a hearing without calling a Green himself (SG2 or NG) while the hearings that a minority chair is more likely to hold tend to be either fully or partially informative (AG or SG1). Thus, the majority chair's relatively stronger incentive to hold a hearing whenever it exists is mainly driven by his incentive to grandstand, reap private benefits, and in case of SG2, let the minority member provide the information which serves as public goods. In contrast, a minority chair's unilateral decision to hold a hearing is driven by information-seeking incentive which benefits all. Table 1 summarizes a chair's decision to hold a hearing depending on his party's majority status and the expected selection of witnesses assuming $c=.2$ and $\theta=.8$ to be consistent with Figure 1 .

Figure 1 displays point predictions of both majority and minority chairs' hearing decisions. In most of the equilibrium space, both types of chairs hold a hearing. However, when $q<.1$ and $d>.75$, neither holds a hearing. If . $1<q<.2$ and $d>.75$, which corresponds to the space marked as (A), only a majority chair holds a hearing, and the resulting hearing will be intended for grandstanding. On the other hand, only a minority chair holds a hearing in a triangular space marked as (B) where SG1 or SG2 is expected and $q<.2 d-.05$, or in a rectangular space marked also as (B) where AG or SG1 is expected and . $438<d$. Therefore, 
this pattern confirms the most interesting and somewhat counterintuitive prediction of this research note: When a principal is moderately biased in favor of the majority member of a committee, having a minority chair as opposed to a majority chair is likely to help the principal make a more informed policy decision.

In addition, I also solved the model assuming a neutral principal that is indifferent between two policy alternative ex ante. Findings suggest that there are situations where only a majority chair holds a hearing, and such a hearing will be either partially informative (SG2) or uninformative (NG) at all. However, experimental evidence from Park discounts the possibility of the former, which implies that having a majority chair is likely to increase the frequency of hearings full of grandstanding. The solution and further discussion are presented in the online appendix.

\section{Discussion}

This research note explored which of the majority and minority committee chairs is more likely to hold an informative hearing under various conditions and provides new theoretical arguments about the informational role of committees as follows. When a floor pivot is biased in favor of the majority member of a committee there are some conditions in which only a minority chair holds a hearing while a majority chair does not, and that hearing is likely to be informative, which is unexpected and surprising. However, when only a majority chair holds a hearing, the hearing tends to be full of grandstanding. Similarly, when a floor pivot is unbiased, hearings that only a majority chair holds is likely to be used for grandstanding.

Therefore, this study makes an important, practical suggestion to legislative bodies with committees that assigning committee chairmanship to minority party members can be 
institutionally desirable not only for the representation of minority voice but also for the

efficiency of the institution through enhanced information transmission.

\section{References}

Anzia, S. F. \& Jackman, M. C. (2013). Legislative Organization and the Second Face of Power: Evidence from US State Legislatures. Journal of Politics, 75(1), 210-224.

Best Practices for Collaborative Policymaking. N.d. Bipartisan Policy Center and Fair Vote. Retrieved from https://d3n8a8pro7vhmx.cloudfront.net/fairvote/pages/611/attachments/original/1450119526/Bes t-Practices-for-Collaborative-Policymaking.pdf?1450119526

Cox, G. W. \& McCubbins, M. D. (2005). Setting the Agenda: Responsible Party Government in the US House of Representatives. Cambridge, UK: Cambridge University Press.

Cox, G. W., Kousser, T. \& McCubbins, M. D. (2010). Party power or preferences? Quasiexperimental evidence from American State Legislatures. The Journal of Politics, 72(3), 803.

DeGregorio, C. (1992). Leadership Approaches in Congressional Committee Hearings. The Western Political Quarterly, 45(4), 971-83.

Diermeier, D. \& Feddersen, T. J. (2000). Information and Congressional Hearings. American Journal of Political Science, 44(1), 51-65.

Evans, C. L. (1991). Leadership in Committee: A Comparative Analysis of Leadership Behavior in the U.S. Senate. Ann Arbor, MI: University of Michigan Press.

Gilligan, T. W. \& Krehbiel, K. (1987). Collective Decision Making and Standing Committees: A Collective Choice Rationale for Restrictive Amendment Procedures. Journal of Law, Economics, and Organization, 3(2), 287-335.

Gilligan, T. W. \& Krehbiel, K. (1989). Asymmetric Information and Legislative Rules with a Heterogeneous Committee. American Journal of Political Science, 33(2), 459-90.

Hedlund, R. D. \& Hamm, K. E. (1996). Political Parties as Vehicles for Organizing U. S. State Legislative Committees. Legislative Studies Quarterly, 21(3), 383-408.

Huitt, R. K. (1954). The Congressional Committee: A Case Study. American Political Science Review, 48, 340-65.

Jackman, M. (2014, August). Discussion on Best Practices for Bipartisan Policymaking. In Roundtable Discussion at the National Conference of State Legislatures. Minneapolis, MN. 
Kasniunas, N. T. (2011). Impact of Interest Group Testimony on Lawmaking in Congress (Doctoral dissertation). Retrieved from

https://ecommons.luc.edu/cgi/viewcontent.cgi?referer=\&httpsredir=1\&article=1219\&context=lu $\underline{\text { c_diss }}$

Martorano, N. (2004). Cohesion or Reciprocity? Majority Party Strength and Minority Party Procedural Rights in the Legislative Process. State Politics \& Policy Quarterly, 4.1, 59.

Park, J. Y. (2017). A Lab Experiment on Committee Hearings: Preferences, Power, and a Quest for Information. Legislative Studies Quarterly, 42, 3-31.

Park, J. Y. (2019). When Do Politicians Grandstand? Measuring Message Politics in Committee Hearings. Journal of Politics, Forthcoming.

Powell, G. B. \& Whitten, G. D. (1993). A Cross-National Analysis of Economic Voting: Taking Account of the Political Context. American Journal of Political Science, 37(2), 391-414. 
Table 1. Chairs' Hearing Decisions

\begin{tabular}{|c|c|c|}
\hline Expected Witness Selection & R chair holds a hearing if ... & B chair holds a hearing if ... \\
\hline NG & $q>.1$ & $q>.2$ \\
\hline AG & $d<.438$ & always \\
\hline SG1 & $q>.4 d-.1$ & always \\
\hline SG2 & $q>.2 d-.05$ & always \\
\hline
\end{tabular}

Note: The utilities are calculated assuming $\mathrm{c}=.2$ and $\theta=.8$ to be consistent with Figure 1. If a chair is indifferent, he holds a hearing with .5 probability. 
Figure 1. Equilibria for Witness Selection and a Chair's Hearing Decision

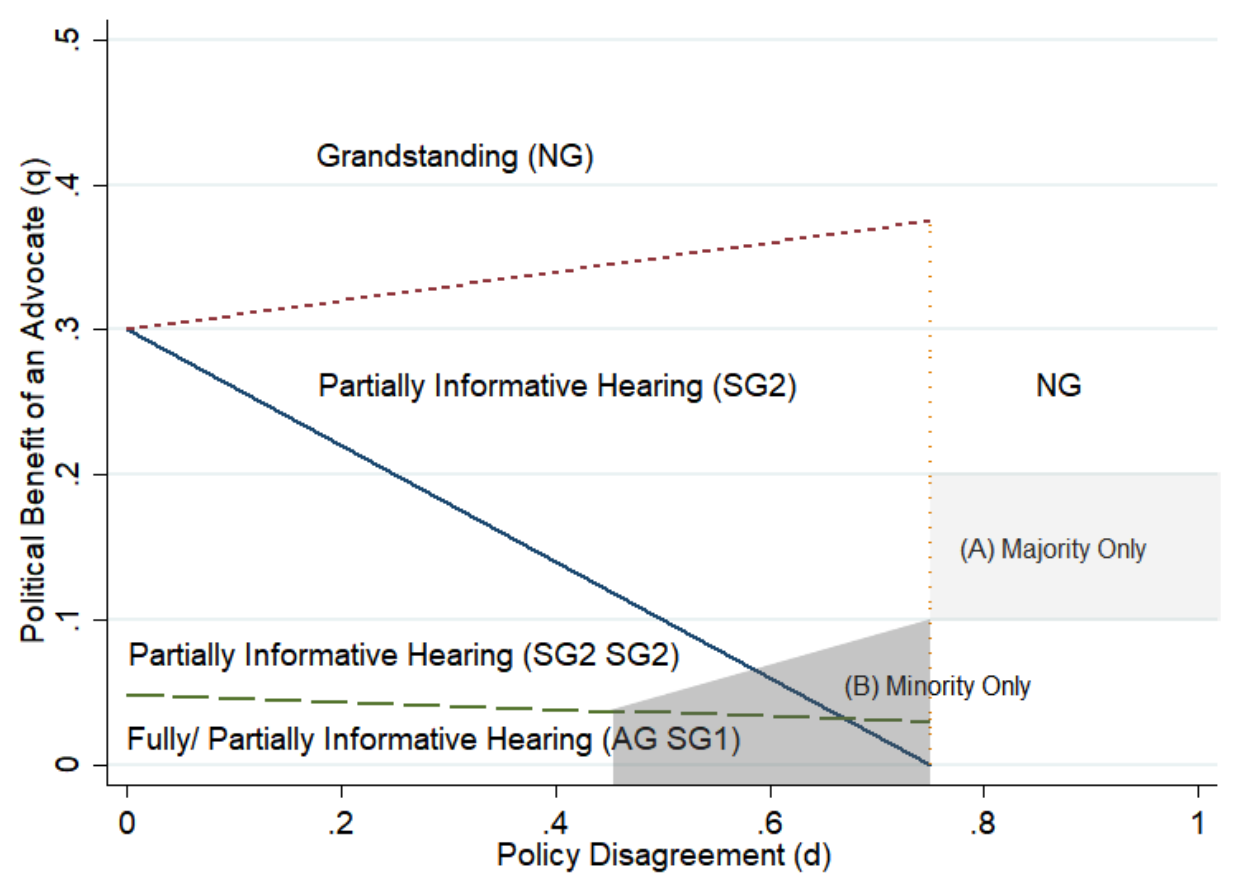

Note: The graph assumes $\theta=.8$. 


\section{Online Supporting Material}

\section{Equilibrium Solution for the Model with a Neutral Principal}

Here, I present theoretical predictions assuming a neutral principal. By being neutral, I mean that a principal prefers implementing a policy that matches the true state of the world such that she receives utility of 1 if the chosen policy matches the state and 0 otherwise.

$$
u_{F}(x, s)= \begin{cases}1, & \text { if } x=s \\ 0, & \text { otherwise }\end{cases}
$$

The equilibrium solution of the model is presented here using backwards induction. The equilibrium strategies for each stage of the game are defined as follows. First, for $i \in\{R, B\}$, let $h^{*}(\cdot)$ be a chair's equilibrium strategy for a hearing decision and it maximizes $E U_{i}$. I denote $h^{*}=1$ for holding a hearing and 0 otherwise. Second, $l_{i}^{*}\left(\cdot \mid l_{\sim i}, h^{*}(\cdot)\right)$ is a committee member $i$ 's equilibrium strategy for witness selection that maximizes $E U_{i}$, if a hearing is held. Third, let $G$ represent a set of messages from the Green group. Then, $f^{*}\left(\cdot \mid G, h^{*}(\cdot)\right)$ is the principal's equilibrium strategy on a policy decision and maximizes $E U_{f}$, given the chair's hearing decision and messages from Green witnesses, if any.

\section{Policy decision by the principal}

If a hearing is not held, the principal randomizes the policy decision based on her prior belief about the state between two alternatives: $P(s=0)=.5$. If a hearing is held, the principal will choose a policy in the following manner:

$$
f^{*}\left(\cdot \mid h^{*}=1\right)=\left\{\begin{array}{c}
x=0, \text { if } E U_{F}\left(x=0 \mid G, h^{*}=1\right)>E U_{F}\left(x=1 \mid G, h^{*}=1\right) \\
x=1, \text { if } E U_{F}\left(x=0 \mid G, h^{*}=1\right)<E U_{F}\left(x=1 \mid G, h^{*}=1\right) \\
\text { randomize, if } E U_{F}\left(x=0 \mid G, h^{*}=1\right)=E U_{F}\left(x=1 \mid G, h^{*}=1\right) .
\end{array}\right.
$$


Below is the principal's expected utility for each policy decision:

$$
\begin{aligned}
& E U_{F}\left(x=0 \mid G, h^{*}=1\right)=P(s=0 \mid G) * 1+P(s=1 \mid G) * 0 \\
& E U_{F}\left(x=1 \mid G, h^{*}=1\right)=P(s=0 \mid G) * 0+P(s=1 \mid G) * 1 .
\end{aligned}
$$

Now, I present posterior beliefs about the state of the world $(s)$ after receiving the messages from the Green groups $(G)$. Given $m \in\{0,1\}$, suppose that $g_{m}$ is the number of Green witnesses sending a message, $m$, such that $g=g_{0}+g_{1}$. First of all, suppose that the probability of receiving certain combination of Greens' messages given each state is

$$
\begin{aligned}
& P(G \mid s=0)=\left(\begin{array}{c}
g \\
g_{0}
\end{array}\right) \theta^{g_{0}}(1-\theta)^{g_{1}} \equiv \alpha \\
& P(G \mid s=1)=\left(\begin{array}{c}
g \\
g_{1}
\end{array}\right) \theta^{g_{1}}(1-\theta)^{g_{0}} \equiv \beta .
\end{aligned}
$$

Then, the posterior beliefs are

$$
\begin{gathered}
P(s=0 \mid G)=\frac{P(G \mid s=0) * P(s=0)}{P(G \mid s=0) * P(s=0)+P(G \mid s=1) * P(s=1)}=\frac{.5 \alpha}{.5(\alpha+\beta)} \\
P(s=1 \mid G)=\frac{P(G \mid s=1) * P(s=1)}{P(G \mid s=0) * P(s=0)+P(G \mid s=1) * P(s=1)}=\frac{.5 \beta}{.5(\alpha+\beta)} .
\end{gathered}
$$

Given that, the principal always selects policy 0 if the following is satisfied:

$$
\begin{gathered}
E U_{F}\left(x=0 \mid G, h^{*}=1\right)>E U_{F}\left(x=1 \mid G, h^{*}=1\right) \\
\alpha>\beta \\
\left(\begin{array}{c}
g \\
g_{0}
\end{array}\right) \theta^{g_{0}}(1-\theta)^{g_{1}}>\left(\begin{array}{c}
g \\
g_{1}
\end{array}\right) \theta^{g_{1}}(1-\theta)^{g_{0}}
\end{gathered}
$$




$$
\left(\frac{\theta}{1-\theta}\right)^{\left(g_{0}-g_{1}\right)}>1
$$

Since $.5<\theta<1,\left(\frac{\theta}{1-\theta}\right)>1$. Therefore, if a hearing is held, the equilibrium strategy for the principal is to implement policy 0 when $g_{0}>g_{1}$ and policy 1 when $g_{0}<g_{1}$. However, even when a hearing is held, if $g_{0}=g_{1}$, the principal will randomize her policy choice with .5 probability.

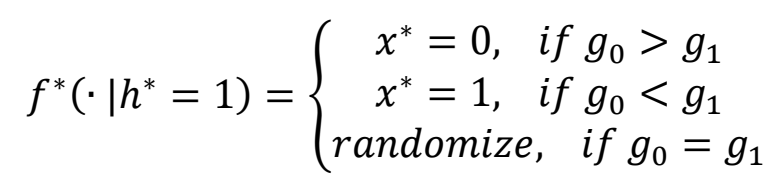

\section{Witness selection by committee members}

Let $p$ be the probability of implementing a policy that matches the state of nature. Then, the policy-based utility is

$$
\begin{gathered}
\sum_{\substack{x \in X \\
s \in S}}\left\{u_{i}(x, s) * P(x \mid s)\right\} \\
=.5\left\{u_{i}(0,0) * p+u_{i}(1,0) *(1-p)+u_{i}(0,1) *(1-p)+u_{i}(1,1) * p\right\} .
\end{gathered}
$$

Given $u_{i}(1,0)=u_{i}(0,1)=0$, the policy-based utility for each committee member reduces to

$$
\sum_{s \in S}\left\{u_{i}(x, s) * P(x \mid s)\right\}=p\left(1-\frac{1}{2} d\right) .
$$

If a hearing is held, the expected utility of a committee member is composed of the policy-based utility, the political utility from inviting advocates, and the cost of holding a hearing as follows: 


$$
E U_{i}=p\left(1-\frac{1}{2} d\right)+a_{i} * q-c, \text { for } i \in\{R, B\}
$$

If a hearing is held, $\mathrm{R}$ chooses two witnesses in any combination of Greens and Reds, while B invites only one witness either from the Green or the Blue group. Since there is a tradeoff between inviting Greens for informational gains and inviting advocates, Reds or Blues, for political gains, the relative size of the marginal utility of one additional Green and that of one additional advocate will determine the equilibrium strategy for witness selection. Thus, I solve for the equilibrium by finding the number of Greens each committee member will invite in the equilibrium.

The first step is to define the marginal probability of implementing a policy matching the state of nature by inviting an additional Green to a hearing. Let $g_{s}, s \in\{0,1\}$, be the number of Greens recommending the policy that matches the true state of the world; and let $g-g_{s}$ be the number of Greens that fail to do so. Since the principal considers messages only from the Green group useful, the probability of implementing a policy that matches the state of nature can be expressed as the following.

If $g$ is odd,

$$
P(x=s \mid G)=\sum_{\left.g_{s}>\mid \frac{g}{2}\right\rceil}^{g}\left(\begin{array}{l}
g \\
g_{s}
\end{array}\right) \theta^{g_{s}}(1-\theta)^{\left(g-g_{s}\right)} \equiv p
$$

If $g$ is even or zero,

$$
\begin{gathered}
P(x=s \mid G)=\sum_{g_{s}>\frac{g}{2}}^{g}\left[\left(\begin{array}{l}
g \\
g_{s}
\end{array}\right) \theta^{g_{s}}(1-\theta)^{\left(g-g_{s}\right)}+.5\left(\begin{array}{l}
g \\
\frac{g}{2}
\end{array}\right) \theta^{\frac{g}{2}}(1-\theta)^{\frac{g}{2}}\right] \equiv p \\
P(x \neq s \mid G) \equiv 1-p
\end{gathered}
$$


The marginal probability of implementing a correct policy by inviting the $\mathrm{n}^{\text {th }}$ number of one additional Green witness can be expressed as $\Delta P(n)$ such that

$$
\Delta P(n) \equiv P(x=s \mid g=n)-P(x=s \mid g=n-1)
$$

As aforementioned, in the equilibrium, the total number of Greens invited will be either one or three, not two. Thus, when only one Green witness is invited, the probability of implementing a policy that matches the true state is equal to $\theta$; and the marginal effect compared to the case without any Greens is $\theta-.5$ because the principal without Greens' messages still has $50 \%$ chances of choosing a policy matching the state. When three Green witnesses are invited, the probability increases to $-2 \theta^{3}+3 \theta^{2} .{ }^{7}$ So, the marginal effect compared to having third additional Green is $-2 \theta^{3}+3 \theta^{2}-\theta$. Formally,

$$
\begin{gathered}
P(x=s \mid g=1)=\theta \\
\Delta P(1)=\theta-.5 \\
P(x=s \mid g=3)=-2 \theta^{3}+3 \theta^{2} \\
\Delta P(3)=-2 \theta^{3}+3 \theta^{2}-\theta .
\end{gathered}
$$

Using these values, Table A1 presents expected payoffs for committee members given their choice of witnesses. Note that the effect of inviting Greens equally rewards both committee members, but the utility of inviting an advocate, Red or Blue, is granted only to the corresponding member. For simpler notation, I use

$$
\lambda \equiv\left(1-\frac{1}{2} d\right)
$$

${ }^{7}\left(\begin{array}{l}3 \\ 3\end{array}\right) \theta^{3}+\left(\begin{array}{l}3 \\ 2\end{array}\right) \theta^{2}(1-\theta)=-2 \theta^{3}+3 \theta^{2}$ 
Table A1. Payoffs for committee members from the selection of witnesses

\begin{tabular}{|c|c|c|}
\hline R member $\mid$ B member & Green & Blue \\
\hline Green-Green & $\left(-2 \theta^{3}+3 \theta^{2}\right) \lambda$ & $\theta \lambda$ \\
& $\left(-2 \theta^{3}+3 \theta^{2}\right) \lambda$ & $\theta \lambda+q$ \\
\hline Green-Red & $\theta \lambda+q$ & $\theta \lambda+q$ \\
& $\theta \lambda$ & $\theta \lambda+q$ \\
\hline Red-Red & $\theta \lambda+2 q$ & $.5 \lambda+2 q$ \\
& $\theta \lambda$ & $.5 \lambda+q$ \\
\hline
\end{tabular}

*Upper entry of each cell is payoffs for R member; lower entry is for B member.

*Note that the cost of hearing $(c)$ has not been subtracted from each payoff because it is not necessary for solving the equilibrium strategies of witness selection once a hearing is held. However, it will be subtracted from the expected utility for solving the chair's choice of holding a hearing in the next section.

\section{Grandstanding equilibrium (No Greens: NG)}

First, there exists an equilibrium where $g=0$. Given that B invites a Blue, R will invite two Reds if . $5 \lambda+2 q \geq \theta \lambda+q$. Likewise, when $\mathrm{R}$ invites two Reds, $\mathrm{B}$ will invite a Blue if $.5 \lambda+q \geq \theta \lambda$. Both conditions are the same. Therefore, both committee members will not invite any Green witnesses if the following condition is met.

$$
\begin{gathered}
E U_{i}\left(g_{i}=1 \mid g_{\sim i}=0\right) \leq E U_{i}\left(g_{i}^{*}=0 \mid g_{\sim i}=0\right) \\
(\theta-.5) \lambda \leq q \\
\Delta P(1) * \lambda \leq q
\end{gathered}
$$

Fully informative equilibrium (All Greens: $A G$ )

Second, there exists an equilibrium where $g=\omega$. Given that B invites a Green witness, R will also invite two Greens if $\left(-2 \theta^{3}+3 \theta^{2}\right) \lambda \geq \theta \lambda+2 q$. Also, when $\mathrm{R}$ invites two Greens, $\mathrm{B}$ will invite a Green if $\left(-2 \theta^{3}+3 \theta^{2}\right) \lambda \geq \theta \lambda+q$. Therefore, the committee members will invite 
witnesses only from the Green group when both conditions are satisfied. However, since the former is a stronger condition unless $q=0$, this equilibrium exists if

$$
\begin{gathered}
E U_{R}\left(g_{R}^{*}=2 \mid g_{B}=1\right) \geq E U_{R}\left(g_{R}=0 \mid g_{B}=1\right) \\
\left(-2 \theta^{3}+3 \theta^{2}-\theta\right) \lambda \geq 2 q \\
\frac{\Delta P(3) * \lambda}{2} \geq q .
\end{gathered}
$$

The following proves that the condition above is possible for certain range of $q$.

Proof 1. There exists $q$ such that $\frac{\Delta P(3) * \lambda}{2} \geq q$.

Given $q \geq 0$ and $.5 \leq \lambda \leq 1$ because $\lambda=\left(1-\frac{1}{2} d\right)$ and $0 \leq d \leq 1$, showing $\Delta P(3) \geq 0$ proves the existence of such $q$.

$$
\begin{gathered}
\Delta P(3)=-2 \theta^{3}+3 \theta^{2}-\theta \\
\quad=-\theta(\theta-1)(2 \theta-1)
\end{gathered}
$$

Given . $5<\theta \leq 1$, if $\theta=1, \Delta P(3)=0$; if $\theta \neq 1$, since $\theta>0$, $(\theta-1)<0$ and $(2 \theta-1)>0, \Delta P(3)>0$. Therefore, $\Delta P(3) \geq 0$. So, there exists $q$ such that $\frac{\Delta P(3) * \lambda}{2} \geq q$.

\section{Partially informative equilibrium (Some Greens: SG)}

Third, I show that there exist equilibria where $0<g<\omega$. As aforementioned, the total number of Green witnesses to be invited in an equilibrium strategy is either one or three because there is no marginal benefit of inviting two Green witnesses instead of one. Hence, the number of Greens in this type of equilibrium is one. 


\section{a. Some Greens 1 (SG1)}

There exists an equilibrium where $\mathrm{R}$ invites one Green and one Red while B invites one Blue $\left(g_{R}=1\right.$ and $\left.g_{B}=0\right)$. Given that $B$ invites a Blue, $R$ will invite one Green and one Red, if $\theta \lambda+$ $q \geq .5 \lambda+2 q$. Also, when $\mathrm{R}$ invites one Green and one Red, B will invite a Blue if $\theta \leq \theta+q$, which is always true. Thus, the equilibrium SG1 exists if $(\theta-.5) \lambda \geq q$, which is same as $\Delta P(1) * \lambda \geq q$

\section{b. Some Greens 2 (SG2)}

There exists an equilibrium where $\mathrm{R}$ invites two Reds while $\mathrm{B}$ invites one Green $\left(\mathrm{g}_{\mathrm{R}}=\right.$ 0 and $\mathrm{g}_{\mathrm{B}}=1$ ). When $\mathrm{R}$ invites two Reds, $\mathrm{B}$ will invite a Green if $\theta \lambda \geq .5 \lambda+q$ that is equal to $\Delta P(1) * \lambda \geq q$. Also, when B invites a Green, $\mathrm{R}$ will select two Reds if $\theta \lambda+2 q \geq\left(-2 \theta^{3}+\right.$ $\left.3 \theta^{2}\right) \lambda$, which is same as $q \geq \frac{\Delta P(3)}{2} * \lambda$. Thus, the equilibrium exists when both conditions are met such that $\frac{\Delta P(3)}{2} * \lambda \leq q \leq \Delta P(1) * \lambda$.

Proof 2. There exists certain range of $q$ such that $\frac{\Delta P(3)}{2} * \lambda \leq q \leq \Delta P(1) * \lambda$.

Given $.5 \leq \lambda \leq 1$, showing $\frac{\Delta P(3)}{2} \leq \Delta P(1)$ proves the existence of such $q$.

$$
\begin{gathered}
\frac{1}{2}\left(-2 \theta^{3}+3 \theta^{2}-\theta\right) \leq \theta-.5 \\
0 \leq 2 \theta^{3}-3 \theta^{2}+3 \theta-1 \\
0 \leq 2\left(\theta-\frac{1}{2}\right)\left(\theta^{2}-\theta+1\right)
\end{gathered}
$$


Since $.5<\theta \leq 1,\left(\theta-\frac{1}{2}\right)>0$. Also, $\left(\theta^{2}-\theta+1\right)>0$ because it is a convex function and its discriminant (D) is -3 which is negative. Thus, the right-hand side is positive.

Therefore, $\frac{\Delta P(3)}{2} \leq \Delta P(1)$ is always true.

Also, note that the equilibrium AG exists if $\frac{\Delta P(3) * \lambda}{2} \geq q$ and the equilibrium SG1 exists if $\Delta P(1) * \lambda \geq q$. Given this proof showing $\frac{\Delta P(3)}{2} \leq \Delta P(1)$, we know that the equilibria $A G$ and SG1 coexist if $\frac{\Delta P(3) * \lambda}{2} \geq q$. The following proves that SG1 is Pareto-suboptimal to AG when they coexist.

Proof 3. If $\frac{\Delta P(3) * \lambda}{2} \geq q$, AG is Pareto-optimal and SG1 is a Pareto-suboptimal Nash Equilibrium.

In $\mathrm{AG}$,

$$
E U_{R}\left(g_{R}=2 \mid g_{B}=1\right)=E U_{B}\left(g_{B}=1 \mid g_{R}=2\right)=\left(-2 \theta^{3}+3 \theta^{2}\right) \lambda
$$

In SG1,

$$
\begin{gathered}
E U_{R}\left(g_{R}=1 \mid g_{B}=0\right)=E U_{B}\left(g_{B}=0 \mid g_{R}=1\right)=\theta \lambda+q . \\
\text { Given } \frac{\Delta P(3)}{2} * \lambda \geq q \text { that is } \frac{1}{2}\left(-2 \theta^{3}+3 \theta^{2}-\theta\right) \lambda \geq q \text {, it is always true that } \\
E U_{R}\left(g_{R}=2 \mid g_{B}=1\right)>E U_{R}\left(g_{R}=1 \mid g_{B}=0\right) \\
\left(-2 \theta^{3}+3 \theta^{2}\right) \lambda>\theta \lambda+q \\
\left(-2 \theta^{3}+3 \theta^{2}-\theta\right) \lambda>q .
\end{gathered}
$$

Figure 1A presents the equilibrium space for witness selection assuming $\theta=.8$. 
Figure 1A. Equilibria for Witness Selection and a Chair's Hearing Decision

With a Neutral Principal

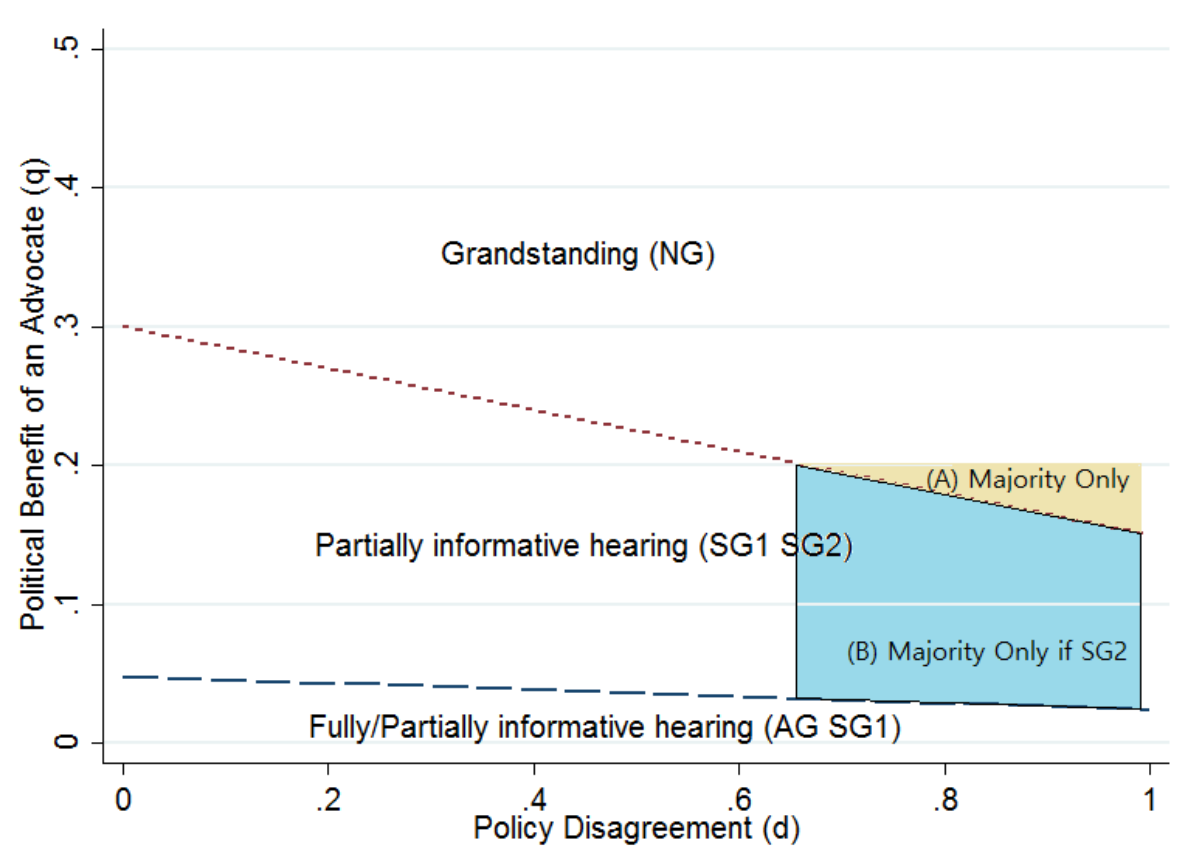

The graph is drawn assuming $\theta=.8$.

\section{Hearing decision by a committee chair}

The chair holds a hearing if

$$
\begin{gathered}
E U_{i}\left(g_{i}^{*} \mid g_{\sim i}, h^{*}=1\right)>E U_{i}\left(h^{*}=0\right) \\
p \lambda+a_{i} * q-c>.5 \lambda \\
(p-.5) \lambda+a_{i} * q>c .
\end{gathered}
$$

If $(p-.5) \lambda+a_{i} * q=c$, he randomizes his choice with .5 probability. Thus, a majority chair is more likely to hold a hearing than a minority chair if $(p-.5) \lambda+a_{R} * q>(p-.5) \lambda+$ $a_{B} * q$ which reduces to $a_{R}>a_{B}$. This condition is satisfied either when $\mathrm{R}$ invites two advocates and B invites a Green (SG2) or when both invite only their advocates (NG). Therefore, R's stronger 
incentive to hold a hearing is mainly driven by his motivation to grandstand.

These comparative statics generate an interesting implication. In the latter case, a majority chair is more likely to hold hearings for a grandstanding purpose than a minority chair. At the same time, however, a majority chair may help information transmission by holding a partially informative hearing (SG2) that a minority chair would not hold. In this sense, depending on the level of committee members' policy disagreement and the benefit of grandstanding on a given issue, having a majority chair may or may not be desirable in terms of information transmission in legislative processes.

However, the majority chair's relatively higher incentive to hold a hearing in the expectation of SG2 may not be noticeable in practice because whenever SG2 is an equilibrium SG1 is also an equilibrium and both types of chairs are equally likely to hold a hearing when SG1 is expected in the witness selection stage. Indeed, in her lab experiment, Park (2017) finds that in the equilibrium space where both SG1 and SG2 are plausible, subjects showed a behavioral pattern that they played SG1 more frequently than SG2. As a result, the net effect of having a majority chair instead of a minority chair is likely to increase only the frequency of hearings characterized as grandstanding. Table A2 provides conditions under which each type of chairs decides to hold a hearing in the expectation of certain types of hearings. The entries of the table are computed assuming $c=.2$ and $\theta=.8$. to be consistent with Figure 1A, and note that $c=.2$ is the value used in the lab experiment of the previous study.

Figure 1A also presents the point predictions of the chair's hearing decisions. In most cases, both types of chairs hold a hearing, but there are two equilibrium spaces in which only a majority chair holds a hearing while a minority chair does not. One that is marked as (A) is when $q<.2$ and NG is expected to be played in the witness selection stage, and the other marked as 
(B) is when $0.67>d$ and SG2 is expected. Note that these two equilibrium spaces may increase or decrease as the cost of hearing changes (e.g. The sizes of both (A) and (B) increase if $c=.3$.), but the theoretical implications remain the same.

Table A2. Chairs' Hearing Decisions with a Neutral Principal

\begin{tabular}{|c|c|c|}
\hline Expected Witness Selection & R chair holds a hearing if ... & B chair holds a hearing if ... \\
\hline NG & $q>.1$ & $q>.2$ \\
\hline AG & $d<.99$ & $d<.99$ \\
\hline SG1 & $q>.15 d-.1$ & $q>.15 d-.1$ \\
\hline SG2 & $q>.075 d-.05$ & $.67>d$ \\
\hline
\end{tabular}

The utilities are calculated assuming $c=.2$ and $\theta=.8$ to be consistent with Figure 1A. If a chair is indifferent, he holds a hearing with .5 probability.

\section{Equilibrium Solution for the Model with a Biased Principal}

\section{Policy decision by the principal}

The principal maximizes her expected utility by selecting one of the two policy alternatives $(x)$ with equal probability of .5 . If a hearing is not held, the expected utility of the principal from choosing policy 0 is .5 and that of choosing policy 1 is $.5(1-d)$. Thus, the principal will always select the policy 0 . However, if a hearing is held, she will select a policy with higher expected utility given the messages from the Green witnesses $(G)$ and randomizes her choice if indifferent between alternative policies by choosing $x=0$ with .5 probability. The expected utility for each policy decision made after a hearing can be formally expressed as the following:

$$
\begin{gathered}
E U_{F}\left(x=0 \mid G, h^{*}=1\right)=P(s=0 \mid G) * 1+P(s=1 \mid G) * 0 \\
E U_{F}\left(x=1 \mid G, h^{*}=1\right)=P(s=0 \mid G) * 0+P(s=1 \mid G) *(1-d) .
\end{gathered}
$$


Note that the principal's expected utility of selecting policy 1 decreases as her level of policy bias $(d)$ increases. Using the posterior belief functions as defined in the previous section, the principal selects policy 0 if and only if the following is satisfied:

$$
\begin{gathered}
E U_{F}\left(x=0 \mid G, h^{*}=1\right)>E U_{F}\left(x=1 \mid G, h^{*}=1\right) \\
\left(\begin{array}{c}
g \\
g_{0}
\end{array}\right) \theta^{g_{0}}(1-\theta)^{g_{1}}>\left(\begin{array}{c}
g \\
g_{1}
\end{array}\right) \theta^{g_{1}}(1-\theta)^{g_{0}}(1-d) \\
\left(\frac{\theta}{1-\theta}\right)^{\left(g_{0}-g_{1}\right)}>1-d \\
d>1-\left(\frac{\theta}{1-\theta}\right)^{\left(g_{0}-g_{1}\right)} .
\end{gathered}
$$

Since $\left(\frac{\theta}{1-\theta}\right)>1$ and $0<d \leq 1$, the condition above is always true if $g_{0} \geq g_{1}$ leading the principal to implement policy 0 , which is consistent with the previous prediction for a neutral principal. However, now with a biased principal, it is possible that she chooses policy 0 even when $g_{0}<g_{1}$ as long as $d$ is large enough. For example, when $\theta=.8, g_{0}=1$ and $g_{1}=2$, the principal will choose policy 0 if $d \geq \frac{3}{4}$. Thus, the comparative statics imply that, as $d$ increases, the probability of the principal choosing policy 0 increases. In other words, the more biased the principal is in favor of policy 0 , the more likely she will choose that policy. For notational convenience, I will use a new term, $\varphi$, for the probability that the principal will choose policy 0 even if $g_{0}<g_{1}$.

$$
P\left(d>1-\left(\frac{\theta}{1-\theta}\right)^{\left(g_{0}-g_{1}\right)} \mid g_{0}<g_{1}\right) \equiv \varphi
$$

The size of $\varphi$ is conditioned not only by the level of partisan disagreement $(d)$ but also by how many Greens are invited in total $(g)$ and the gap between the number of different 
messages from them, $\left(g_{0}-g_{1}\right)$. Thus, let $\varphi_{g}$ denote the value of $\varphi$ for a given number of Greens invited $(g)$.

Then, the equilibrium strategy of the principal if a hearing is held is as follows:

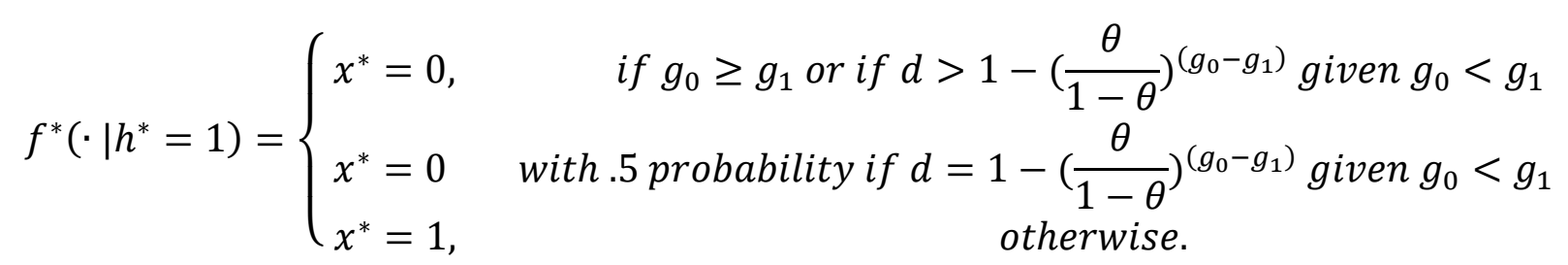

(Proposition PD-Bias) Given that the principal is biased in favor of policy 0 by $d$, if a hearing is not held, the principal always selects policy 0 . If a hearing is held, she selects policy 0 , if $g_{0} \geq$ $g_{1}$, or if $g_{0}<g_{1}$ and $d>1-\left(\frac{\theta}{1-\theta}\right)^{\left(g_{0}-g_{1}\right)}$; and policy 1 , otherwise. However, if she is indifferent about choosing either of the policies, she randomizes her choice with .5 probability. As the level of bias (d) increases, she is more likely to choose policy 0.

As a result, as the principal is more biased, the probability of implementing a policy that matches the state $(s)$ increases if the state is $s=0$ but decreases if the state is $s=1$. Given that $p$ represents the probability for a neutral principal to implement a policy matching the state, this probability for a biased principal is modified as the following:

$$
\begin{aligned}
& P(x=s \mid s=0, G)=p+(1-p) \varphi \\
& P(x=s \mid s=1, G)=p(1-\varphi) .
\end{aligned}
$$

2. Witness selection by committee members

Since the probability of implementing a policy that matches the true state has changed, the expected utilities of the committee members have to be modified accordingly. 


$$
\begin{gathered}
E U_{i}=E\left(u_{i}(x, s)\right)+q * a_{i}-c \text { for } i \in\{R, B\} \\
E\left(u_{R}(x, s)\right)=\sum_{\substack{x \in X \\
s \in S}}\left\{u_{R}(x, s) * P(x \mid s)\right\}=\frac{1}{2}\{p+(1-p) \varphi+p(1-\varphi)(1-d)\} \\
=p(1-\varphi)\left(1-\frac{d}{2}\right)+\frac{\varphi}{2} \\
E\left(u_{B}(x, s)\right)=\sum_{\substack{x \in X \\
s \in S}}\left\{u_{B}(x, s) * P(x \mid s)\right\}=\frac{1}{2}[\{p+(1-p) \varphi\}(1-d)+p(1-\varphi)] \\
=p(1-\varphi)\left(1-\frac{d}{2}\right)+\frac{\varphi(1-d)}{2} .
\end{gathered}
$$

Thus, given $P(x=s \mid g=1)=\theta, P(x=s \mid g=3)=-2 \theta^{3}+3 \theta^{2}$, and $\left(1-\frac{1}{2} d\right)=\lambda$,

$$
\begin{gathered}
E\left(u_{R}(x, s) \mid g=1\right)=\theta \lambda\left(1-\varphi_{1}\right)+\frac{\varphi_{1}}{2} \\
E\left(u_{R}(x, s) \mid g=3\right)=\left(-2 \theta^{3}+3 \theta^{2}\right)\left(1-\varphi_{3}\right) \lambda+\frac{\varphi_{3}}{2} \\
E\left(u_{B}(x, s) \mid g=1\right)=\theta \lambda\left(1-\varphi_{1}\right)+\frac{\varphi_{1}(1-d)}{2} \\
E\left(u_{B}(x, s) \mid g=3\right)=\left(-2 \theta^{3}+3 \theta^{2}\right)\left(1-\varphi_{3}\right) \lambda+\frac{\varphi_{3}(1-d)}{2} .
\end{gathered}
$$

The arguments above can be solved further by fixing $\theta$ at a certain value because, then, the size of $\varphi$ can be calculated depending on the level of disagreement on policy $(d)$ and the combination of Greens' messages $\left(g_{m}\right)$ as presented below. 


\section{Calculation of the probability $\varphi_{g}$}

Assuming $\left.\theta=.8, \varphi=P\left(d \geq 1-\left(\frac{\theta}{1-\theta}\right)\right)^{\left(g_{0}-g_{1}\right)} \mid g_{0}<g_{1}\right)$ takes conditional values as follows:

a) If $g=1$, it is always true that $g_{1}-g_{0}=1$ given $g_{1}>g_{0}$.

$$
\varphi_{1}= \begin{cases}1, & \text { if } d \geq \frac{3}{4} \\ 0, & \text { otherwise. }\end{cases}
$$

b) If $g=2$, it is always true that $g_{1}-g_{0}=2$ given $g_{1}>g_{0}$.

$$
\varphi_{2}=\left\{\begin{array}{l}
1, \text { if } d \geq \frac{15}{16} \\
0, \text { otherwise }
\end{array}\right.
$$

c) If $g=3$, then $g_{1}-g_{0}=1$ or 3 given $g_{1}>g_{0}$.

If $g_{1}-g_{0}=1$,

$$
\varphi_{3}=\left\{\begin{array}{l}
1, \text { if } d \geq \frac{3}{4} \\
0, \text { otherwise }
\end{array}\right.
$$

If $g_{1}-g_{0}=3$,

$$
\varphi_{3}=\left\{\begin{array}{l}
1, \text { if } d \geq \frac{63}{64} \\
0, \text { otherwise. }
\end{array}\right.
$$

In summary, if $d<\frac{3}{4}, \varphi_{1}=\varphi_{2}=\varphi_{3}=0$ regardless of the number of Greens $(g)$ and their messages $\left(g_{m}\right)$. Likewise, if $d \geq \frac{63}{64}, \varphi_{1}=\varphi_{2}=\varphi_{3}=1$, always. If $\frac{3}{4} \leq d<\frac{15}{16}, \varphi_{1}=1$ and $\varphi_{2}=0$; and if $\frac{15}{16} \leq d<\frac{63}{64}, \varphi_{1}=\varphi_{2}=1$. However, when $\frac{3}{4} \leq d<\frac{63}{64}$, the size of $\varphi_{3}$ varies depending on $g_{m}$ such that $\varphi_{3}=1$ if $g_{1}-g_{0}=1 ; \varphi_{3}=0$ if $g_{1}-g_{0}=3$. Assuming that 
committee members are aware of this contingency and take it into account when making decisions, I further clarify the expected size of $\varphi_{3}$ as the following:

$$
\begin{gathered}
\mathrm{P}\left(g_{1}-g_{0}=1 \mid g=3\right)=\frac{1}{2} *\left\{P\left(g_{0}=1, g_{1}=2 \mid s=0\right)+P\left(g_{0}=1, g_{1}=2 \mid s=1\right)\right\} \\
=\frac{1}{2} *\left\{\left(\begin{array}{c}
g \\
g_{0}
\end{array}\right) \theta^{g_{0}}(1-\theta)^{g_{1}}+\left(\begin{array}{c}
g \\
g_{1}
\end{array}\right) \theta^{g_{1}}(1-\theta)^{g_{0}}\right\} \\
=\frac{1}{2} *\left\{\left(\begin{array}{l}
3 \\
1
\end{array}\right) \cdot 8(1-.8)^{2}+\left(\begin{array}{l}
3 \\
2
\end{array}\right) \cdot 8^{2}(1-.8)\right\} \equiv x \\
\begin{aligned}
\mathrm{P}\left(g_{1}-g_{0}=3 \mid g=3\right)=\frac{1}{2} *\left\{P\left(g_{0}=0, g_{1}=3 \mid s=0\right)+P\left(g_{0}=0, g_{1}=3 \mid s=1\right)\right\} \\
=\frac{1}{2} *\left\{\left(\begin{array}{l}
3 \\
0
\end{array}\right)(1-.8)^{3}+\left(\begin{array}{l}
3 \\
3
\end{array}\right) \cdot 8^{3}\right\} \equiv y \\
\mathrm{P}\left(g_{1}-g_{0}=1 \mid g=3, g_{1}>g_{0}\right)=\frac{x}{x+y}=.48 \\
\mathrm{P}\left(g_{1}-g_{0}=3 \mid g=3, g_{1}>g_{0}\right)=\frac{y}{x+y}=.52 .
\end{aligned}
\end{gathered}
$$

Thus, if $g=3, g_{1}>g_{0}$, and $\frac{3}{4} \leq d<\frac{63}{64}, \varphi_{3}$ is 1 with .48 probability when $g_{1}-g_{0}=$ 1 ; and 0 with .52 probability when $g_{1}-g_{0}=3$. Then, the expected size of $\varphi_{3}$ under this condition will be 48 as shown below:

$$
E\left(\varphi_{3} \mid g=3, g_{1}>g_{0}, \frac{3}{4} \leq d<\frac{63}{64}\right)=.48 * 1+.52 * 0=.48
$$

Therefore, the equilibrium of witness selection is a non-linear function of $d$ such that there will be cut-points at $\frac{3}{4}$ if $g=1$; at $\frac{15}{16}$ if $g=2$; and at $\frac{3}{4}$ and $\frac{63}{64}$ if $g=3$. If $\theta=.8$ and $d<\frac{3}{4}$ or $\frac{63}{64} \leq$ $d$, then $\varphi_{1}=\varphi_{2}=\varphi_{3}$. 
Table A3 below presents expected payoffs for each of the committee members.

Table A3. Payoffs for committee members from the selection of witnesses

\begin{tabular}{|c|c|c|}
\hline R member $\mid$ B member & Green & Blue \\
\hline Green-Green & $E\left(u_{R}(x, s) \mid g=3\right)$ & $E\left(u_{R}(x, s) \mid g=1\right)$ \\
& $E\left(u_{B}(x, s) \mid g=3\right)$ & $E\left(u_{B}(x, s) \mid g=1\right)+q$ \\
\hline Green-Red & $E\left(u_{R}(x, s) \mid g=1\right)+q$ & $E\left(u_{R}(x, s) \mid g=1\right)+q$ \\
& $E\left(u_{B}(x, s) \mid g=1\right)$ & $E\left(u_{B}(x, s) \mid g=1\right)+q$ \\
\hline Red-Red & $E\left(u_{R}(x, s) \mid g=1\right)+2 q$ & $.5+2 q$ \\
& $E\left(u_{B}(x, s) \mid g=1\right)$ & $\frac{(1-d)}{2}+q$ \\
\hline
\end{tabular}

Upper entry of each cell is the payoff for R; lower entry is for B. Note that the cost of hearing (c) has not been subtracted from each of the payoffs in this table because it is not necessary for solving the equilibrium strategies of witness selection once a hearing is held.

As in the model with a neutral principal, there are three types of pure-strategy Bayesian-

Nash equilibrium.

\section{Grandstanding equilibrium (No Greens: NGBias)}

(Proposition NG-Bias) Both $R$ and $B$ members do not invite any Green witnesses if $q \geq t_{2}$.

For an equilibrium where nobody invites Greens to exist, the following two conditions have to be satisfied:

$$
\begin{gathered}
E U_{R}\left(g_{R}^{*}=0 \mid g_{B}=0\right) \geq E U_{R}\left(g_{R}=1 \mid g_{B}=0\right) \\
.5+2 q \geq \theta \lambda\left(1-\varphi_{1}\right)+\frac{\varphi_{1}}{2}+q \\
q \geq\left(1-\varphi_{1}\right)\left(\theta \lambda-\frac{1}{2}\right) \equiv t_{1}, \quad \text { and } \\
E U_{B}\left(g_{B}^{*}=0 \mid g_{R}=0\right) \geq E U_{B}\left(g_{B}=1 \mid g_{R}=0\right) \\
\frac{(1-d)}{2}+q \geq \theta \lambda\left(1-\varphi_{1}\right)+\frac{\varphi_{1}(1-d)}{2}
\end{gathered}
$$




$$
q \geq\left(1-\varphi_{1}\right)\left(\theta \lambda-\frac{1-d}{2}\right) \equiv t_{2}
$$

Since $d>0, t_{2}>t_{1}$. Thus, the second argument addressing B's strategy serves as a stronger condition for this equilibrium to exist. Therefore, both committee members will not invite any Green witnesses if $t_{2} \leq q$.

Also, the comparative statics suggests several interesting points. First of all, for the given political value of inviting an advocate, $q$, the equilibrium becomes more likely as $\theta$ decrease and as $d$ increases. ${ }^{8}$ The implication is that committee members tend to grandstand in a hearing as Greens' messages are less accurate; as the principal is more biased; and as the members have more divergent interests over a policy. Likewise, for the given values of $\theta$ and $d$, the equilibrium becomes more likely as $q$ increases, which suggests that committee members tend to hold a stage-managed hearing as they have larger political interest by doing so.

\section{Fully informative hearing (All Greens: AGBias)}

(Proposition AG-Bias) Both $R$ and B invite witnesses only from the Green group if $q \leq t_{3}$.

Second, there is an equilibrium where both committee members invite Green witnesses only if the following two conditions are satisfied:

$$
\begin{gathered}
E U_{R}\left(g_{R}^{*}=2 \mid g_{B}=1\right) \geq E U_{R}\left(g_{R}=0 \mid g_{B}=1\right) \\
\frac{1}{2}\left[\left\{\left(-2 \theta^{3}+3 \theta^{2}\right)\left(1-\varphi_{3}\right)-\theta\left(1-\varphi_{1}\right)\right\} \lambda+\frac{\varphi_{3}-\varphi_{1}}{2}\right] \geq q, \quad \text { and } \\
E U_{B}\left(g_{B}^{*}=1 \mid g_{R}=2\right) \geq E U_{B}\left(g_{B}=0 \mid g_{R}=2\right)
\end{gathered}
$$

\footnotetext{
${ }^{8}$ Note $\lambda=1-\frac{d}{2}$. Thus, $t_{2}=\left(1-\varphi_{1}\right)\left\{\theta-\frac{1}{2}-d\left(\frac{\theta-1}{2}\right)\right\}$. Therefore, $t_{2}$ decreases in $d$.
} 


$$
\frac{1}{2}\left[\left\{\left(-2 \theta^{3}+3 \theta^{2}\right)\left(1-\varphi_{3}\right)-\theta\left(1-\varphi_{2}\right)\right\} \lambda+\frac{\left(\varphi_{3}-\varphi_{2}\right)(1-d)}{2}\right] \geq q
$$

Given $\varphi_{1}=\varphi_{2}=\varphi_{3}$ if $\theta=.8$ and $d<\frac{3}{4}$ or $\frac{63}{64} \leq d$, the arguments above are reduced as the following, respectively:

$$
\begin{gathered}
q \leq \frac{\Delta P(3) * \lambda(1-\varphi)}{2} \equiv t_{3} \quad \text { and } \\
q \leq \Delta P(3) * \lambda(1-\varphi) .
\end{gathered}
$$

It shows that the former condition defining R's strategy is a stronger condition than the latter. Therefore, there is an equilibrium All Greens (AG) if the former holds, and I label the upper bound for $q$ as $t_{3}$.

If $\theta=.8$, for example, the equilibrium exists either when $d<\frac{3}{4}$ or when $\frac{63}{64} \leq d$ and $q=0$ because $\varphi_{1}=\varphi_{2}=\varphi_{3}=1$. However, it does not exist when $\frac{3}{4} \leq d<\frac{63}{64}$.

Proof 4. If $\frac{3}{4} \leq d<\frac{63}{64}$, the equilibrium $A G$ does not exist.

First, assume that the second condition that defines B's strategy is more binding, and it will be true if the following is satisfied:

$$
\left(\theta \lambda-\frac{1}{2}\right)\left(\varphi_{1}-\varphi_{2}\right)>\frac{\left(\varphi_{2}-\varphi_{3}\right) d}{2}
$$

Again, for further solution, I assume $\theta=.8$. Then, $\varphi_{1}=1, \varphi_{2}=0$, and $E\left(\varphi_{3}\right)=.48$. The condition above reduces to $d<1.875$ which is always true since $0<d \leq 1$. Therefore, the second condition addressing B's strategy serves as a stronger condition and it becomes -.047 - 
$.036 d \geq q$. However, since $0 \leq q$ by assumption, the condition does not hold in any case. Thus, the equilibrium AG does not exist if $\frac{3}{4} \leq d<\frac{15}{16}$.

Second, consider $\frac{15}{16} \leq \mathrm{d}<\frac{63}{64}$. Then, since $\varphi_{1}=\varphi_{2}=1$, the condition $\left(\theta \lambda-\frac{1}{2}\right)\left(\varphi_{1}-\varphi_{2}\right)>\frac{\left(\varphi_{2}-\varphi_{3}\right) d}{2}$ reduces to $d<0$, which is false. Thus, it leads to a conclusion that R's equilibrium condition is stronger than B's. R's condition is . $103-.117 d \geq q$.

However, even when $d=\frac{15}{16}$, the right-hand side becomes negative, -.007. Since $0 \leq q$ by assumption, the condition does not hold. Therefore, the equilibrium AG does not exist if $\frac{15}{16} \leq$ $\mathrm{d}<\frac{63}{64}$

\section{Partially informative equilibrium (Some Greens: SGBias)}

(Proposition SG1-Bias) R member invites one Green and one Red and B does not invite any Green if $q \leq t_{1}$.

(Proposition SG2-Bias) B invites one Green and $R$ does not invite any Greens if $t_{3} \leq q \leq t_{2}$.

First, I consider the equilibrium SG1. The equilibrium exists if both of the following two conditions are satisfied:

$$
\begin{gathered}
E U_{R}\left(g_{R}^{*}=1 \mid g_{B}=0\right) \geq E U_{R}\left(g_{R}=0 \mid g_{B}=0\right) \\
\left(1-\varphi_{1}\right)\left(\theta \lambda-\frac{1}{2}\right) \geq q, \quad \text { and } \\
E U_{B}\left(g_{B}^{*}=0 \mid g_{R}=1\right) \geq E U_{B}\left(g_{B}=1 \mid g_{R}=1\right) \\
\theta \lambda\left(1-\varphi_{1}\right)+\frac{\varphi_{1}(1-d)}{2}+\mathrm{q} \geq \theta \lambda\left(1-\varphi_{2}\right)+\frac{\varphi_{2}(1-d)}{2} .
\end{gathered}
$$


I further solve the equilibrium assuming $\theta=.8$. Note that the first condition for $\mathrm{R}$ player is equivalent to $t_{1} \geq q$. The latter condition for $\mathrm{B}$ depends on the values of $\varphi_{1}$ and $\varphi_{2}$. Since if $d<\frac{3}{4}$ or $d \geq \frac{15}{16}$, then $\varphi_{1}=\varphi_{2}$, the argument reduces to $q \geq 0$ which is always true. Thus, the equilibrium SG1 exists when the first condition $t_{1} \geq q$ is satisfied for the given the range of $d$. However, if $d \geq \frac{15}{16}, t_{1}=0$ because $\varphi_{1}=1$. Therefore, SG1 exists only when $q=0$ if $d \geq \frac{15}{16}$.

On the other hand, if $\frac{3}{4} \leq d<\frac{15}{16}$, then $\varphi_{1}=1$ and $\varphi_{2}=0$. Thus, $t_{1}=0$, and the first condition reduces to $0 \geq q$, which suggests that $\mathrm{R}$ selects one Green in this case only when $q=$ 0 . However, the second condition reduces to $q \geq d\left(\frac{1-\theta}{2}\right)+\left(\theta-\frac{1}{2}\right)$, and the right-hand side is a non-zero positive value because $d>0$ and $.5<\theta<1$. Therefore, since there is no $q$ that satisfies both conditions, the equilibrium, SG1, does not exist if $\frac{3}{4} \leq d<\frac{15}{16}$.

Second, the equilibrium SG2 exists if the following two conditions are satisfied:

$$
\begin{gathered}
E U_{R}\left(g_{R}^{*}=0 \mid g_{B}=1\right) \geq E U_{R}\left(g_{R}=2 \mid g_{B}=1\right) \\
\theta\left(1-\varphi_{1}\right) \lambda+\frac{\varphi_{1}}{2}+2 q \geq\left(-2 \theta^{3}+3 \theta^{2}\right)\left(1-\varphi_{3}\right) \lambda+\frac{\varphi_{3}}{2}, \quad \text { and } \\
E U_{B}\left(g_{B}^{*}=1 \mid g_{R}=0\right) \geq E U_{B}\left(g_{B}=0 \mid g_{R}=0\right) \\
q \leq\left(1-\varphi_{1}\right)\left(\theta \lambda-\frac{1-d}{2}\right)=t_{2} .
\end{gathered}
$$

If $d<\frac{3}{4}$ or $\frac{63}{64} \leq d, \varphi_{1}=\varphi_{3}$. Then, the first condition reduces to $q \geq t_{3}$. The second condition is equivalent to $q \leq t_{2}$. Thus, for the given range of $d$, SG2 exists if $t_{3} \leq q \leq t_{2}$. 
Especially, if $\frac{63}{64} \leq d$, then $\varphi_{1}=\varphi_{3}=1$ so that $t_{2}=t_{3}=0$. Therefore, the equilibrium exists only when $q=0$.

If $\frac{3}{4} \leq d<\frac{63}{64}$, then $\varphi_{1}=1$ and $\mathrm{E}\left(\varphi_{3}\right)=.48$. Note that $\lambda=1-\frac{d}{2}$.

For R member to invite no Greens,

$$
\begin{gathered}
E U_{R}\left(g_{R}^{*}=0 \mid g_{B}=1\right) \geq E U_{R}\left(g_{R}=2 \mid g_{B}=1\right) \\
\theta\left(1-\varphi_{1}\right) \lambda+\frac{\varphi_{1}}{2}+2 q \geq\left(-2 \theta^{3}+3 \theta^{2}\right)\left(1-\varphi_{3}\right) \lambda+\frac{\varphi_{3}}{2} \\
q \geq .103-.117 d .
\end{gathered}
$$

For B member to invite a Green,

$$
\begin{gathered}
E U_{B}\left(g_{B}^{*}=1 \mid g_{R}=0\right) \geq E U_{B}\left(g_{B}=0 \mid g_{R}=0\right) \\
q \leq\left(1-\varphi_{1}\right)\left(\theta \lambda-\frac{1-d}{2}\right)=t_{2} \\
q \leq 0 .
\end{gathered}
$$

Since $0 \leq q$, for B to invite a Green, $q$ has to be 0 . For both conditions to be met, $d \geq$ $\frac{22}{25}$. Therefore, if $\frac{3}{4} \leq d<\frac{22}{25}$, the equilibrium SG2 does not exist; if $\frac{22}{25} \leq d<\frac{63}{64}$, it exists for $q=0$.

3. Hearing decision by the committee chair

The chair holds a hearing if the following condition is satisfied:

$$
\begin{gathered}
E U_{i}\left(g_{i}^{*} \mid g_{\sim i}, h^{*}=1\right)>E U_{i}\left(h^{*}=0\right) \\
p \lambda(1-\varphi)+\frac{\varphi}{2}+a_{R} * q-.5>c \quad \text { for } R \\
p \lambda(1-\varphi)+\frac{\varphi(1-d)}{2}+a_{B} * q-\frac{1-d}{2}>c \quad \text { for } B
\end{gathered}
$$

and randomizes by holding a hearing with .5 probability if indifferent. 
A majority chair is more likely to hold a hearing than a majority chair if the left-hand side of (15) is greater than that of (16) so that $2 q\left(a_{R}-a_{B}\right)>d(1-\varphi)$.

Note: For Table 2 which assumes $c=.2$ and $\theta=.8$, the following holds:

1) If NG, $p=.5, \varphi=1, a_{R}=2$, and $a_{B}=1$.

2) If AG, $p=.896, \varphi=0, a_{R}=0$, and $a_{B}=0$ if $d<.75 ; E(\varphi)=.48$ if . $75<d<$ $63 / 64 ; \varphi=1$ if $63 / 64<d$. However, note that AG is not played if $d>.75$.

3) If SG1, $p=.8, \varphi=0, a_{R}=1$, and $a_{B}=1$ if $d<.75 ; \varphi=1$ otherwise. However, note that SG1 is not played if $d>.75$

4) If SG2, $p=.8, \varphi=0, a_{R}=2$, and $a_{B}=0$ if $d<.75 ; \varphi=1$ otherwise. However, note that SG2 is not played if $d>.75$ 